\title{
The Concentric Circle Revisited: Allocentrism and Self in a Contemporary Chinese Community
}

\author{
Weining C. Chang ${ }^{1,2}$, Lynn Lee ${ }^{3}$ \\ ${ }^{1}$ School of Psychology, University of Western Australia, Perth, Australia \\ ${ }^{2}$ Duke-National University of Singapore Graduate School of Medicine, Singapore City, Singapore \\ ${ }^{3}$ National University of Singapore, Singapore City, Singapore \\ Email: weining.chang@uwa.edu.au,weiningchu.chang@duke.nus.edu.sg
}

Received November $17^{\text {th }}, 2011$; revised January $2^{\text {nd }}, 2012$; accepted February $16^{\text {th }}, 2012$

\begin{abstract}
Contemporary literature has extensively documented the connection between allocentrism and interdependence in self-construals. The present report comprises two studies that aimed to extend this literature by investigating the traditional Chinese concentric circle model of self-representation in a modern Asian community. Study 1 comprised a series of focus group discussions $(\mathrm{N}=35,4$ males and 31 females, average age 20) to determine the qualitative content of self-construal. Participants reported a construct called the "true self", with a content similar to the private self, and a number of social-selves varying along the perceived intimacy of the self-other relationship. In Study 2, 120 participants (all females, average age 19) were tested on their level of allocentrism and then allocated to an allocentric (top $25 \%, \mathrm{~N}=$ 30 ) and an idiocentric (bottom 25\%; N = 30) group. Participants responded to the Twenty-Self Statement-Test (TST) on seven relationship scenarios with various levels of intimacy. Their responses were coded into collective/private/public self categories. Allocentrism and scenarios were found to have main and interactive effects on the proportions of self categories. The results were interpreted as supporting the graded nature of Chinese self-other relationships and a modified concentric circle self-representation in modern Asia.
\end{abstract}

Keywords: Allocentrism; Situation Sensitivity; Chinese Model of Self

\section{Introduction}

The centrality of self-concept in psychological functions has been well documented (see for instance, Baumeister, 1998). Anthropological studies (e.g., Allan, 1997; Doi, 1985; Geertz, 1973; Roland, 1988) and cross-cultural reviews (e.g., Markus \& Kitayama, 1991; Triandis, 1990; Triandis, Bontempo, Villareal, Asia, \& Lucca, 1988) have converged on the theme that each culture provides its own paradigm to guide the individual to make sense of the self, others and the world (Geertz, 1973; Miller, 1984; Shweder \& Borne, 1984; Spiro, 1993). Therefore, the self and the culture are seen to constitute one another mutually (Markus \& Kitayama, 2010). Social institutions (Hsu, 1981), religious beliefs (Inada, 1997), values, customs, norms, and interpersonal relations (Curtis, 1991) further act as information filters that selectively guide the attention of the individual to certain aspects, presumably at the expense of attention to other aspects of the self (Fiske, Kitayama, Markus, \& Nisbett, 1998). In this paper we explore the self-construal of young Chinese living in a modern industrialized society (Clammer, 1993). We show that their self-construal reflects the conceptual framework of the person inherent within the Chinese cultural tradition-a tradition that places a strong emphasis on intricately differentiated interpersonal relations (Hsu, 1981; Tu, 1985 ) with a concentric circle conceptualization of the individual self (Fei, 1947/1984; Munro, 1969, 1985).

\section{Culture and Self}

Towards the end of the last millennium, two themes gained acceptance in the widely disputed arena of selfhood in different cultural contexts. The first theme was made popular by series of research on the tripartite division of the private, the collective and the public self-representations (for instance, Greenwald \& Pratkanis, 1984; Triandis, 1990) and the second theme is best presented by the Markus and Kitayams's (1991) influential review of the independence and interdependence of self-construal (see also, Markus \& Kitayama, 2010). Both themes are related to a cultural dimension - individualism/collectivismfirst presented by anthropologists Parsons and Shils (1951) and then used by the psychologist Hofstede (1980/1984) in his multinational study. The independence and interdependence of self-construal (Markus \& Kitayama, 1991), as well as the proportions of collective/private/public self (Greenwald \& Pratkanis, 1984) were proposed to be related to the relative emphasis of a culture on the collective or collectivism (Markus \& Kitayama, 1991; Triandis, 1989).

Many studies on collectivism/individualism and self-construal have been carried out by contrasting self-representations of Asians with those in the West. In contrast, Asian investigators often resist the blanket characterization of Asians as "collectivists” (see Matsumoto \& Kudo, 1996; Yang, 1992). They contend that the construction of collectivism-individualism as a single dimension is overly simplistic. Collectivism and individualism can take on a variety of forms in different cultures and each can make a unique contribution to the formulation of self-concept. We propose that it would be conceptually more transparent to investigate each dimension separately rather than combining them and treating them as one construct or a single 
dimension.

In the present report, we focus on the construct of collectivism at the individual level—allocentrism (Triandis, 1990)—and propose that allocentrism is not homogeneously distributed in modern Asia, and that subscription to it varies considerably across Asian populations. Cultures of these modern Asian communities often show a bifurcation of subscription to more or less collectivism (Chang, Wong, \& Koh, 2003; Yang, 1996). Within a given Asian population, we can identify individuals who are more allocentric and those who are less allocentric. For convenience, the terms "allocentrists" and "idiocentrists" are used in this paper to label those who are strongly allocentric and those who are weakly allocentric, respectively.

\section{Allocentrism and Social Sensitivity}

Allocentrics have been found to be more sensitive to situations that involve social others and to respond differentially to a variety of social scenarios (Triandis, Chen, \& Chan, 1988). This sensitivity is evident because allocentrics tend to attribute behavioral consequences to others (Choi, Nisbett, \& Norenzayan, 1999; Morris \& Peng, 1994) and are more likely to delegate the choice of their own actions to significant others (Hernandez \& Iyangar, 2001). Compared to idiocentrics, allocentrics are less likely to attribute their behavior to the attitudes of individuals (Kashima, Siegal, Tanaka, \& Kashima, 1992). These findings provide evidence to support that others who are significant to the individual have been included in the meaning of self by and functions as the self (Markus \& Kitayama, 1991) for allocentrics. This is the psychological interdependence that forms the foundation of the interdependent self (Markus \& Kitayama, 1991, 2010).

The Chinese live in a world with finely defined layers of relationships (Hsu, 1981) that makes in- and out-group differentiation gradated rather than binary, resembling ripples emanating from the individual or a concentric circle with the individual self in the center (Fei, 1947, 1984; Munro, 1969, 1985) (see Figure 1).

We hypothesized that the Chinese system of self-representation might be structured by this perceived gradation of selfother relationships. Other Chinese researchers have proposed similar views: King (1992) in Hong Kong, and Yang (1996), Hwang (1992) and Yu, Chang and Hu (1992) in Taiwan.

Summarizing the above, we further hypothesized that there might be an allocentrism-and-situation interactive effect on

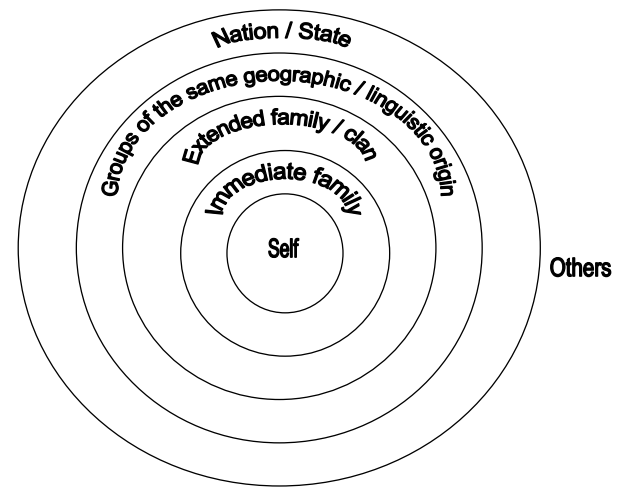

Figure 1.

A schematic presentation of self in the traditional Chinese social context. self-construal in addition to the main individual effects of allocentrism and situation that affect the content of the interdependent self-representation of the Chinese. The concentric circle of self-representation in Chinese might be a result of the interaction effect of allocentrism and sensitivity to different relationship situations.

In the present study, we used a multi-staged approach (Chang, 2000) to explore the selfhood of contemporary Chinese. We employed sequentially focus group discussions on the participants' perception and meaning of the self and the relationships experienced in their normal everyday life, followed by a standard test of self-representation using the Twenty Self-statement Test (Kuhn \& MacPartland, 1954) with the private, collective and public self-construal categorization (Greenwald \& Pratkanis, 1984) in an experimental study by systematically manipulating the situation variables to "map" the complex Chinese self-representations.

\section{Empirical Studies}

Two empirical studies were conducted. Study 1 used focused group discussions (Morgan, 1997) to elicit reports of the qualitative content of the prototype of self-representation in contemporary Chinese participants. Using the results of Study 1, Study 2 tested the self-construals in relation to the allocentrism and social relationships of individuals. Several hypotheses were generated on the basis of the proposed Chinese selfhood. Adopting the conventional tripartite division of self-statements, we hypothesized that:

1) Different facets of the Chinese self-representation, operationalized as the composition of the private versus the social: i.e., public and collective self-representations, would be elicited by their respective situation cues, operationalized as the imagined presence of different others.

2) Different compositions of the private/social self-representations are systematically organized along a dimension of perceived intimacy with the target other: i.e., the concentric circle representation of the self.

3) An individual's collectivist orientation: i.e., allocentricism, influences the situation variation in self-representation.

4) The concentric circle of self-representation is an interactive effect of allocentrism and situation cues.

We tested these hypotheses by eliciting spontaneous selfstatements in multiple situations.

\section{Study 1. Focus Group Discussions on Self and Self-Other Relationships in Singaporean Daily Life}

Participants: Thirty-five university students (4 males and 31 females; average age $=20$, all Chinese) were asked to discuss issues relating to self, self-knowledge and self-representations in their normal everyday life. Six focus group discussion sessions were held with 5 - 8 participants in each session.

Procedure: The participants were grouped into six discussion groups. Each group was given the following topics to discuss. What do I think myself is? How do I know myself? From what sources do I obtain self-related information? With whom do I interact often? What do I tell them about myself? The senior author led all the discussions. Participants were encouraged to make as many responses as possible regardless of whether they considered the comment to be relevant or not. Participants' responses were recorded verbatim. 
Results: A content analysis was conducted on the written records to identify the major themes. The participants made a clear distinction between the self that they considered "true" (participants' word), and self-statements that involved the self with different social others in various situations. We labeled the latter the "social self", according to James (1890, 1978). The true self was described as containing personal dispositionscharacteristics of the self as an individual. The participants traced their knowledge of this true self to two major sources: self-reflection as well as direct and perceived feedback from social others.

With regard to social selves, there seemed to be two major categories: self-in-relation-to-specific others (Curtis, 1991), and self-as-a-part-of-a-collective or common identity (Brewer, 2002). The participants referred to the category of common identity as "dawo" (big self) where the individual characteristics, "xiaowo" (small self), were masked by the common group identity. Participants reported that they were not normally conscious of their collective identities: being Singaporeans or being Chinese. These identities became salient and relevant in their behavior only on National Day or ethnic festivals, such as the Chinese New Year. They were more aware of self in different relationships in normal everyday social transactions.

The participants reported that they would "share" their true self when appropriate, and that the appropriateness was defined by their perceived intimacy with the target other. The situations considered to be appropriate were defined by the perceived intimacy with the intended audience.

It appeared that without being aware of the literature, the participants concurred with Sternberg and Grajek's (1984) definition of intimacy in interpersonal relationships: the tendency to disclose or share your private thoughts and feelings - what the participants considered to be "true self".

We then asked the participants to rate the level of intimacy of the people with whom they normally interacted. There was an almost unanimous consensus in the following rating: from most intimate to least intimate, which corresponds to most disclosure to least disclosure of the private self, self-close friends/the immediate family-classmates-acquaintances-strangers/distant relatives (see Figure 2).

Conclusion and Discussion: The small group discussions yielded qualitative information concerning the construction of

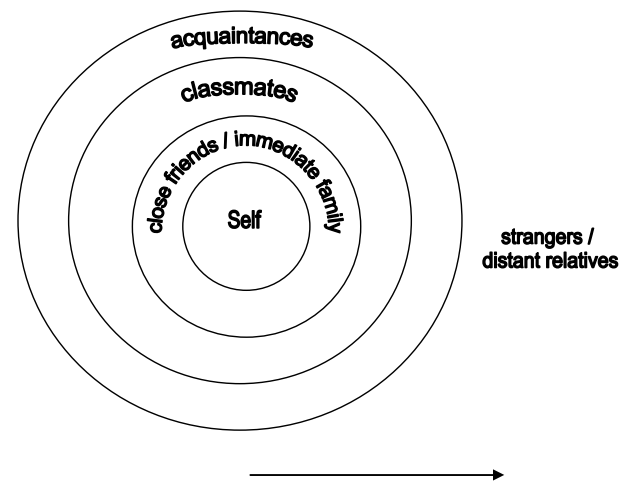

Decreasing intimacy \& confidence; decreasing private $\&$ individual aspects of self; and increasing role \& stereotypical aspects of self

Figure 2.

Self and social relations reported by Singaporean students. the self that involves a body of knowledge of the "true" self, the content of which could be classified as the "private self" in James $(1890,1978)$. From this body of knowledge of the "true self", the participants selectively presented certain aspects of their true self to others. Depending on the perceived intimacy of the relationship with the interacting other, the participants presented a different aspect of the self, the part that they considered to be relevant to the other party. They were keenly aware of the effects of others on the self and its functioning (Stepel \& Koomen, 2001). They considered the self to be intimately embedded in the specific relationship in which they were engaged. Thus, they had a keen sense of the relational self (Anderson, 2002) or relational selves as an integral part of their self-representations. In summary, these young Singaporean participants presented a sketch of the self that embodied the self/social self conceptualization of James (1890/1989) who observed, more than a century ago, that "There are as many social selves as there are people who know" the individual; the contemporary Singaporean participants reported that they presented different aspects of the self to others. However, there is a systematic selection criterion, in terms of which aspect of the self to present, that is the perceived intimacy with the other person.

\section{Study 2. Twenty Self-Statement Test in Different Social Contexts}

This study was designed to test the following hypotheses: 1) self statements vary as a function of the situations operationalized as different target audiences; 2) with increasing intimacy, the proportion of private self will increase, at the same time, the proportion of collective self will decrease; and 3) the collectivist orientation-allocentrism of an individual will interact with the situation to produce greater situational variation in the private/collective self-statements.

Participants: One hundred and twenty female undergraduate students, with average age of 19.1 years, participated in this study. Only female students were recruited because the Faculty of Arts and Social Sciences has a predominantly female (90\%) student body, and an all-female sample would be more representative of the student population.

The participants were randomly recruited from the National University of Singapore's psychological research participant pool. They were administered the Singapore Collectivism Scale (Singh \& Vasoo, 1994) described below. On the basis of the scores on the Collectivism scale, participants were categorized into high collectivists (top 25\%) ( $\mathrm{N}=30$ )-labeled allocentrics-and low collectivists (bottom $25 \%)(\mathrm{N}=30)$-labeled idiocentrics—following the terminology of Triandis (1989).

Instruments: Two instruments were administered: the Collectivism scale (Singh \& Vasoo, 1994) and the Twenty Selfstatement Test. Modeled after Hui's (1988) individualism and collectivism scale, Singh and Vasoo's (1994) Singapore Collectivism Scale was designed on the basis of individual attitudes towards the relevant collectives in Singapore: family, spouse, neighbors and co-workers. This scale was used to assess the participants' allocentrism. The internal reliability of this scale was found to be 0.90 . The participants were instructed to complete the test in response to the following scenarios:

1) Control situation-imagine you are sitting by yourself, write down 20 items to answer the question: "Who am I?"

2) Immediate family-imagine you are sitting with your parents and siblings, write down 20 items to answer the ques- 
tion: "Who am I?"

3) Close friends-imagine you are sitting with close friends, write down 20 items to answer the question: "Who am I?"

4) Classmates_imagine you are sitting with classmates, write down 20 items to answer the question: "Who am I?"

5) Extended family-imagine a distant aunt came to visit you, write down 20 items to answer the question: "Who am I?"

6) Acquaintances-imagine you are sitting with some acquaintances, write down 20 items to answer the question: "Who am I?"

7) Total stranger-imagine you are sitting next to a total stranger, write down 20 items to answer the question: "Who am I?"

Dependent Measures: Participants' responses were coded in terms of private self, collective self, and public self (Greenwald \& Pratkanis, 1984; Triandis, 1989; Triandis, Bontempo, Villareal, Asai, \& Lucca, 1988). Because the responses were limited to 20 items, the proportion of each self category from the overall responses was used as the dependent measure.

Analyses: The proportion of each type of response (private versus collective versus public) in each scenario for each subject was calculated. For each situation, the respective numbers of private, collective and public self-statements were divided by the total number of self-statements made by the participant for that situation.

Two raters coded the self-responses, and the inter-rater reliability was found to be 0.85 . The final results were generated by discussions and consensus between the raters.

Results: The overall mean proportions were $74 \%$ for private self, $23 \%$ for collective self and $3 \%$ for public self. Because public self-responses accounted for only $3 \%$ of the data, they were not analyzed further (see Table 1).

A $2 \times 7 \times 2$ analysis of variance was performed with one between-subjects factor (allocentrism) and two within-subject factors (social scenarios and the type of self-response). A significant within-subject main effect on response type was found $(\mathrm{F}(1,51)=264.76 ; p<0.001)$. As mentioned above, the proportion of the private self $(\mathrm{M}=0.74)$ was much greater than that of the collective self $(\mathrm{M}=0.23)$ (see Figure 3 ).

A significant interaction effect was found between allocentrism and scenarios on the response proportions $(F(6,306)=$ 2.12; $p<0.05)$.

Table 1.

Mean proportion of Private-Collective self statements as a function of high and low allocentrism.

\begin{tabular}{ccccc}
\hline & \multicolumn{2}{c}{ Private } & \multicolumn{2}{c}{ Collective } \\
\hline & Idiocentrist & Allocentrist & Idiocentrist & Allocentrist \\
Control (myself) & 0.83 & 0.83 & 0.13 & 0.14 \\
Best Friend & 0.84 & 0.73 & 0.15 & 0.24 \\
Immediate Family & 0.84 & 0.75 & 0.12 & 0.21 \\
Extended Family & 0.72 & 0.62 & 0.26 & 0.35 \\
Classmate & 0.84 & $0.70^{*}$ & 0.14 & $0.30^{*}$ \\
Acquaintance & 0.85 & $0.64^{* *}$ & 0.14 & $0.34^{* *}$ \\
Total Stranger & 0.68 & 0.69 & 0.32 & 0.31 \\
\hline
\end{tabular}

Note: ${ }^{*} p<0.015 ;{ }^{* *} p<0.00$.

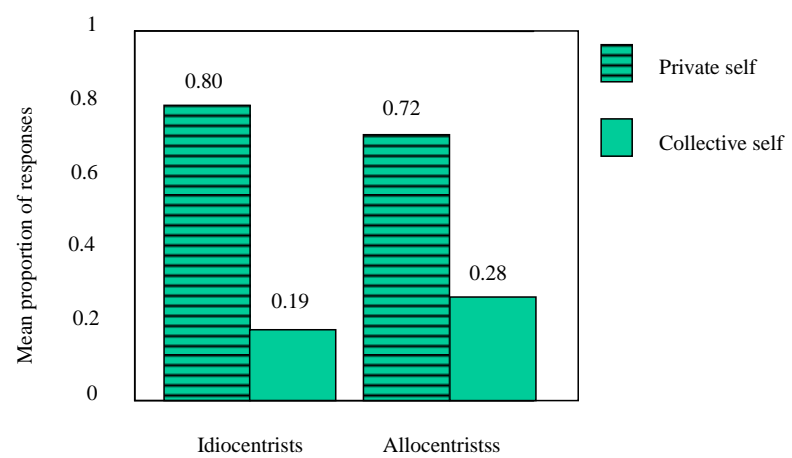

Figure 3.

Proportions of private and collective self-statements in different situations.

We report below the analysis of the private self and the collective self separately.

Private Self: A significant main effect of situation was found in both allocentrics $(\mathrm{F}(6,306)=3.85 ; p<0.001)$ and idiocentrics $(F(6,306)=3.85 ; p=0.001)$. The only significant differences found in the pair comparison across the allocentrics and idiocentrics were in the classmate and the acquaintance situations, where the idiocentrists reported greater proportions of private self.

Visual inspection of the means revealed small differences across all situations and in the right direction: i.e., an increasing proportion of private self with increasing perceived intimacy with the target audience. These small but systematic differences did not reach statistical significance, which might be due to the small sample size and hence the low power of the statistical test. By plotting the proportions of the private self across situations, a finer and graded differentiation of the proportion of private self by allocentrics was found. This was mirrored in the increasing proportions of the collective self with decreasing intimacy (see Figure 4).

Collective Self: Main effects were found for allocentrism (F $(1,51)=8.65 ; p=0.005)$ and situation $(\mathrm{F}(6,306)=9.17 ; p<$ $0.001)$ in the collective self-representation. Allocentrics reported a higher proportion of collective self-statements than idiocentrics across all situations. Situational variations were found for both allocentrics and idiocentrics; with increasing rated intimacy, a decrease in collective self-representation was found, an pair comparison showed significant differences in collective self in the acquaintance and classmate situations, where allocentrists reported a significantly higher proportion of collective self.

Plotting the proportion of reported collective self across situations revealed that allocentrics made a finer differentiation (see Figure 4).

Conclusion and Discussion: This study represents a direct empirical test of our hypotheses that Chinese self-construal is a complex structure that consists of a private and multiple social selves defined by different relationships. The results also confirmed the Triandis et al. (1988) observation of the "target sensitivity" of allocentrics in social interactions. The allocentrism and situation (relationship scenario) interactive effect suggests that allocentrics were more sensitive to situation differences in the reporting of their private self. The self-representation in this modern Chinese community reflects James's notion of multiple social selves, and that, to these modern Chinese participants, 


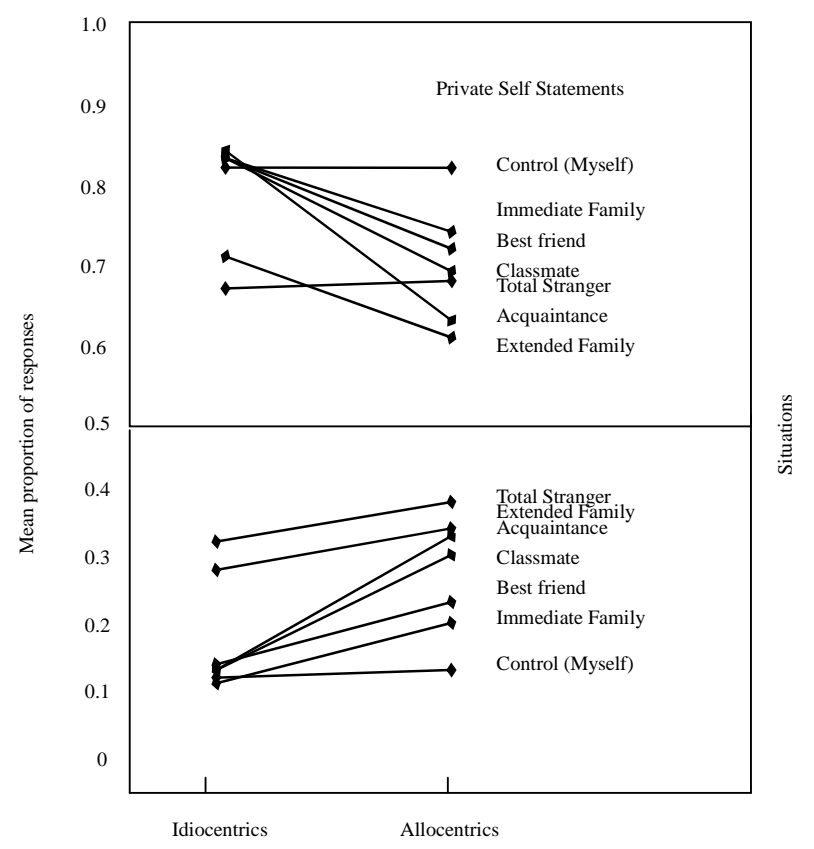

Figure 4.

Mean proportion of self-statements as a function of Individualismcollectivism.

there are as many social selves as there are different relationships. The multiple social selves found in the participants were arranged systematically along the range of perceived intimacy of relationships with the target audience.

\section{General Discussion}

Anthropological studies have proposed that the Chinese selfhood, operationalized as a system of self-representations, incorporates not only internal dispositional information about the individual but also the internalized layers of self-other relationships, "guanxi", arranged according to the perceived intimacy/confidence with the target audience.

Results of the focus group discussions provided preliminary information that Chinese in the modern context have an awareness of information related to internal, individual characteristics - what they called the true self-as well as a sensitivity to their relationships with others. In this sense, Singaporeans, like Chinese in other regions of the world, are relationship- or "guanxi"-oriented.

The richness of the self-focused information about the "true self" is in sharp contrast to most contemporary self-studies involving Chinese. This provides proof that, although they are relationship-oriented, the Chinese are keenly aware of the existence of their internal, dispositional attributes. However, the awareness of internal attributes is subject to the influence of perceived intimacy in the relationship context. When the Twenty Self-statement Test was administered without situational cues, Singapore Chinese participants reported higher percentages of the private self than of the collective self. Similar findings have been reported in Hong Kong with Chinese university students (Bond \& Cheung, 1983). Using a different methodology, Yu, Chang and $\mathrm{Hu}$ (1992) found that Taiwanese university students showed a faster reaction time in recognizing trait-related terms than role- and relationship-related terms, suggesting that the private self, the awareness of individual traits, is very much alive and prevalent in Chinese participants. Our study not only concurred with this finding but further extended the literature by finding that the reporting of this private self, termed "true self” by our participants, is tempered by the perceived intimacy of the target audience.

The very small proportion of the public self-the self in relation to the general public would be what Chinese sociologists Fei (1947, 1984) and King (1992) would have predicted. These scholars observed that the Chinese place great emphasis on personal, specific "guanxi" rather than on the impersonal generalized others.

Our findings support the context-dependent nature of representing abstract personal traits by the Chinese. It is interesting to note that, without explicit situational cues, our participants' responses were highly similar to those found by collapsing self-statements across multiple scenarios. This suggests that the data obtained from Asian participants using the "standard" decontextualised procedure might be an algebraic average of the trait information across multiple trait-in-context schemata. Thus, either by introducing the contextual cues (Cousins, 1989) or by collapsing data across multiple situations as we did, we might be able to "sift" out the abstract personal characteristics used by Asian participants.

The participants told us during the focus group interviews that collective identities, such as being Chinese or Singaporean-the possible "dawo" identities-were not relevant to them most of the time in their normal everyday life. The contextual cues that were important to them were interpersonal relationships, and they presented more person-in-relationship statements. This led us to a concern over the categorization of these two different types of social self-common bond and common identity (Brewer \& Gardner, 1996) - under the same category called "collective self". In our coding of the collective self, following conventional practice, we did not differentiate between "guanxi" "wo"-relational self, and "dawo". We coded selfstatements such as "I am a Singaporean" as a collective identity in the categories of collective selves, and "I am your niece" as a role in self-with-other statements. It is proposed that future studies differentiate these different types of collective self, using measures that appropriately define the various selfconstruals (see Brewer, 2002), because they might have different psychological and behavioral implications.

The participants reported different proportions of the private/collective self in different situations. This supported our hypothesis that the Chinese self-construal is a complex structure that consists of many and varied relationships-i.e., many self-schemata, each representing a different unit of self-insituation information. The results of our studies also reinforce the findings of Trafimow, Triandis and Goto (1991), in that there might be different types of cognitive constructs for the private self and the collective self and that different priming would elicit different aspects of self (see, for instance, Brewer \& Gardner, 1996).

The multiple self-with-(specific)-other and self-in-situation/ relationship schemata also suggest that the concept of "collectivism", defined as the relative emphasis of the collective, might vary from culture to culture (see, for instance, Traindis \& Gelfand, 1998). For the Chinese, cultural collectivism and the corresponding individual allocentricism seem to be a situation-dependent trait. Therefore, to determine the behavioral consequences of allocentricism, situation cues in the form of 
perceived relationships with the target audience have to be introduced (Kashima \& Hardie, 2000). It is also suggested that scenarios-context specific cues-are more appropriate for assessing the self-related psychological processes (see Matsumoto, Weissman, Preston, Brown, \& Kupperbusch, 1997; Triandis, Chen, \& Chan, 1998) in Asian populations.

More importantly, we proposed that the scenarios-as experimental stimuli-have to afford the same psychological meaning to the participants as that intended by the researcher for the investigation to be culturally valid (Cole, 1996). The scenarios that we used were constructed on the basis of the rated intimacy of relationships derived from the focus group discussions with Singaporean students. The experimental manipulation was therefore ecologically valid in the present study.

Juxtaposed between East and West, Singaporeans are not homogeneous in their collectivist orientations. We felt that this cultural diversity needed to be addressed. As we hypothesized, the idiocentric Singaporeans (low collectivists) reported a higher proportion of private self and less situational variation than the allocentric Singaporeans (high collectivists). This intra-cultural variation further confirms the predictions of Triandis (1989) of high target sensitivity and more collective selfreference as consequences of collectivism.

Comparing the self-construal of these contemporary Chinese with what Confucian scholars might have envisioned (see Figure 1), the Singaporean self-construal mirrored a change in the social structure of modern Chinese society (see Figure 2). Closest friends rivaled immediate family members in the inner layer of the self; while distant relatives were relegated to a similar position as strangers in the rating of intimacy. Matsumoto and Kudoh (1996) found that Asians (Japanese in their study) in modern Asia have a conceptualization of society that reflects the self-other relations of a modern society rather than those of strictly hierarchical traditional Asian communities. Selfhood is shaped and formed by internalized self-other relations, and varies as the social structure changes. There are as many interdependent selves as there are forms of interdependence. The independent versus interdependence dichotomy or the public, collective and private self tripartite have both been proven to fall short as explanations of Chinese self-representations. As Ashmore, Deaux and McLaughlin-Volpe (2004) observed, the construct of collective identity needs to be expanded to include the different senses of interdependence and selfcategorizations. The self-representations of the Chinese certainly provide an excellent case in point.

\section{Limitations}

This study was based on empirical data drawn from mostly female university students in Singapore. As such, a limitation should be noted: being mostly female, the participants might be more socially oriented, that is allocentric, than the population as a whole. However, being better educated and predominantly English speaking, the participants, who represented the modern sector of the population, were also more attuned to internal self-characteristics (Yang, 1996). The effects of gender, use of languages and education are important factors that might influence selfhood. Future studies should systematically address these issues.

The popular tripartite division of self-representations-private, collective and public self-construals - was used in the present study to explore Chinese selfhood; however, the appli- cation of this method was more of a convenience to enable a comparison of the findings with those of other studies on culture and self. The various terms denoting the Chinese self-“wo" are not readily translatable into contemporary terminology of private, collective and public selves. More recent developments in the construct of the relational self (Anderson, 2002; Curtis, 1991) provide an interesting complement to the private and social self dichotomy (see also Kashima \& Hardie, 2000). The Chinese have developed a much finer gradation in self-other relationships (Hsu, 1981) than is permitted in the conventional three-way division. Theirs is a "guanxi"-oriented, specific relationship-oriented society. The self, "Wo", construed within this cultural and linguistic context would be best described and analyzed by employing the Chinese lexical system of the self and its many variations.

\section{REFERENCES}

Allen, D. (Ed.) (1997). Culture and self: Philosophical and religious perspectives, East and West. Honolulu, HI: University of Hawaii Press.

Anderson, S. M. (2002). The relational self: An interpersonal socialcognitive theory. Psychological Review, 109, 619-645.

doi:10.1037/0033-295X.109.4.619

Ashmore, R. D., Deaux, K., \& McLaughlin-Volpe, T. (2004). An organization framework for collective identity: Articulation and significance of multidimensionality. Psychological Bulletin, 130, 80114. doi:10.1037/0033-2909.130.1.80

Baumeister, R. F. (1998). The self. In D. T. Gilbert, S. T. Fiske, \& G. Lindzey (Eds.), The handbook of social psychology (4th ed., Vol. 1, pp. 635-679). Boston, MA: McGraw-Hill Co., Inc.

Bond, M. H., \& Cheung, T. S. (1983). The spontaneous self-concept of college students in Hong Kong, Japan and the United States. Journal of Cross-Cultural Psychology, 14, 153-171. doi:10.1177/0022002183014002002

Brewer, M. B. (2002). The many faces of social identity: Implications for political psychology. Political Psychology, 22, 115-125. doi:10.1111/0162-895X.00229

Brewer, M. B., \& Gardner, W. (1996). Who is this "we"? Levels of collective identity and self-regulations. Journal of Personality and Social Psychology, 71, 89-93. doi:10.1037/0022-3514.71.1.83

Chang, W. C. (2000). In search of the Chinese in all the wrong places. Journal of Psychology in the Chinese Societies, 1, 125-142.

Chang, W. C., Wong, W. K., \& Koh, J. B. K. (2003). Chinese values in Singapore: Traditional and modern. Asian Journal of Social Psychology, 6, 5-29. doi:10.1111/1467-839X.t01-1-00007

Choi, I., Nisbett, R. E., \& Norenzayan, A. (1999). Causal attribution across cultures: Variation and universality. Psychological Bulletin, 125, 47-63. doi:10.1037/0033-2909.125.1.47

Clammer, J. (1993). Religious pluralism and Chinese beliefs in Singapore. In H. T. Cheu, (Ed.), Chinese beliefs and practices in Southeast Asia (pp. 199-224). Selangor Darul Ehsan: Pelanduk Publications.

Cole, M. (1996) Cultural psychology: A once and future discipline. Cambridge, MA: Harvard University Press.

Cousins, S. D. (1989). Culture and self-perception in Japan and the United States. Journal of Personality and Social Psychology, 56, 124-131. doi:10.1037/0022-3514.56.1.124

Curtis, R. C. (Ed.) (1991). The relational self: Theoretical convergence in psychoanalysis and social psychology. New York, NY: Guilford Press. 282-314.

Doi, L. T. (1985). The anatomy of self: The individual versus society. Tokyo: Kodansha.

Fei, X. T. (1947/1984). The native soil of China. Hong Kong: Lienhe Publishing Co. Ltd.

Fiske, A. P., Kitayama, S., Markus, H. R., \& Nisbett, R. E. (1998). The cultural matrix of social psychology. In D. T. Gilbert, S. T. Fiske, \& G. Lindzey (Eds.), The handbook of Social Psychology (4th ed., Vol. 2, pp. 915-981). Boston, MA: McGraw-Hill Co., Inc. 
Geertz, C. (1973). Person times and conduct in Bali. Interpretation of cultures. New York, NY: Basic Books. 360-411.

Greenwald, A. G., \& Pratkanis, A. R. (1984). The self. In R. S. Wyer, \& T. K. Scrull (Eds.), Handbook of social cognition (Vol. 3, pp. 129-178). Hillsdale, NJ: Earlbaum.

Hernandez, M., \& Iyangar, S. S. (2001). What drives whom? A cultural perspective on human agency. Social Cognition, 19, 269-294. doi:10.1521/soco.19.3.269.21468

Hui, H. C. (1988). Measurement of individualism-collectivism. Journal of Research in Personality, 22, 17-36. doi:10.1016/0092-6566(88)90022-0

Hofsted, G. H. (1980/1984). Culture's consequences: International differences in work related values. Thousand Oaks, CA: Sage Publications.

Hsu, F. L. K. (1981). Americans and Chinese: Passage to differences (3rd ed.). Honolulu, HI: University of Hawaii Press.

Hwang, K. K. (1992) The Chinese power fame. Taipei: Ju Liu Publishing Co.

Inada, K. A. (1997) Buddho-Taoist and Western metaphysics of the self. In D. Allen (Ed.), Culture and self: Philosophical and religious perspectives, East and West (pp. 83-96). Boulder, CO: Westview Press.

James, W. (1890, 1978). The principles of psychology. New York, NY: Dover Publishing Co.

Kashima, E., \& Hardie, E. S. (2000). The development and validation of the Relational, Individual and Collective self-aspects (RIC). Asian Journal of Social Psychology, 3, 19-48. doi:10.1111/1467-839X.00053

Kashima, Y., Siegal, M., Tanaka, K., \& Kashima, E. (1992). Do people believe behaviours are consistent with attitudes? Towards a cultural psychology of attribution processes. British Journal of Social Psychology, 31, 111-124. doi:10.1111/j.2044-8309.1992.tb00959.x

King, A. Y. C. (1992). Chinese society and culture. Hong Kong: Oxford University Press.

Kuhn, M. H., \& McPartland, T. S. (1954). An empirical investigation of self-attitudes. American Sociological Review, 19, 68-76. doi:10.2307/2088175

Markus, H., \& Kitayama, S. (1991). Culture and the self: Implications for cognition, emotion and motivation. Psychological Review, 98, 224-253. doi:10.1037/0033-295X.98.2.224

Markus, H. R., \& Kitayama, S. (2010). Culture and selves: A cycle of mutual constitution. Perspectives on Psychological Sciences, 5, 420430. doi:10.1177/1745691610375557

Matsumoto, D., \& Kudoh, T. (1996). Changing patterns of individualism and collectivism in the United States and Japan. Culture and Psychology, 2, 77-107. doi:10.1177/1354067X9621005

Matsumoto, D., Weissman, M. D., Preston, K., Brown, B. R., \& Kupperbusch, C. (1997). Context-specific measurement of individualism-collectivism on individual level: The individualism-collectivism interpersonal assessment Inventory. Journal of Cross-cultural Psychology, 28, 734-767. doi:10.1177/0022022197286006

Miller, J. G. (1984). Culture and the development of everyday social explanation. Journal of Personality and Social Psychology, 46, 961978. doi:10.1037/0022-3514.46.5.961

Morgan, D. L. (1997). Focus groups as quantitative research (2nd ed.). Thousand Oaks, CA: Sage Publications.

Morris, M., \& Peng, K. (1994). Culture and causes: American and Chinese attributions for social and physical events. Journal of Personality and Social Psychology, 67, 949-971. doi:10.1037/0022-3514.67.6.949

Munro, D. (1969). The concept of man in early China. Palo Alto, CA: Stanford University Press.
Munro, D. (Ed.) (1985). Individualism and holism: Studies in confucian and Taoist values. Ann Arbor, MI: Centre for Chinese Studies, University of Michigan.

Parsons, T., \& Shils, E. (Eds.) (1951). Toward a general theory of action. Cambridge, MA: Harvard University Press.

Roland, A. (1988). In search of self in India and Japan: Toward a cross-cultural psychology. Princeton, NJ: Princeton University Press.

Shweder, R. A., \& Bourne, E. J. (1984). Does the concept of the person vary cross-culturally? In R. A. Shweder, \& R. A. LeVine (Eds.), Culture theory: Essays on mind, self and emotion (pp. 158-199). Cambridge: Cambridge University Press.

Singh, R., \& Vasoo, S. (1994). Collectivism as a dimension of personality. A research report. Singapore City: National University of Singapore.

Spiro, M. F. (1993). Is the western conception of the self "peculiar" within the context of the world cultures? Ethos, 21, 107-153. doi:10.1525/eth.1993.21.2.02a00010

Stepel, D. A., \& Koomen, W. (2001). I, we, and the effects of others on me: How self-construal level moderates social comparison effects. Journal of Personality and Social Psychology, 80, 766-781. doi:10.1037/0022-3514.80.5.766

Sternberg, R. J., \& Grajek, S. (1984). The nature of love. Journal of Personality and Social Psychology, 47, 312-329. doi:10.1037/0022-3514.47.2.312

Trafimow, D., Triandis, H. C., \& Goto, S. G. (1991). Some tests of the distinction between the private self and the collective self. Journal of Personality and Social Psychology, 60, 649-655. doi:10.1037/0022-3514.60.5.649

Triandis, H. C. (1989). The self and social behavior in differing cultural contexts. Psychological Review, 96, 506-520. doi:10.1037/0033-295X.96.3.506

Triandis, H. C. (1990). Cross-cultural studies of individualism and collectivism. In J. J. Berman (Ed.), Nebraska symposium on Motivation, 1989: Cross-cultural Perspectives (Vol. 37, pp. 41-133). Lincoln, NE: University of Nebraska Press.

Triandis, H. C., \& Gelfand, M. J. (1998). Converging measurement of horizontal and vertical individualism and collectivism. Journal of Personality and Social Psychology, 74, 118-128. doi:10.1037/0022-3514.74.1.118

Triandis, H. C., Bontempo, R., Villareal, M. J., Asai, M., \& Lucca, N. (1988). Individualism and collectivism: Cross-cultural perspectives on self-in-group relations. Journal of Personality and Social Psychology, 34, 323-338. doi:10.1037/0022-3514.54.2.323

Triandis, H. C., Chen, X. P., \& Chan, D. K. S. (1998). Scenarios for the measurement of collectivism and individualism. Journal of CrossCultural Psychology, 29, 278-289. doi:10.1177/0022022198292001

Tu, W. (1985). Confucian thought: Selfhood as creative transformation. Albany, NY: State University of New York Press.

Yang, C. F. (1992). Do Chinese really have a collectivist orientation? Exploration of the Chinese value system (Monograph of the Centre for Han Xue (Chinese Studies)). Hong Kong: Chinese University of Hong Kong.

Yang, K. S. (1996). The psychological transformation of the Chinese people as a result of societal modernization. In M. H. Bond (Ed.), Handbook of Chinese psychology (pp. 479-498). Hong Kong: Oxford University Press.

Yu, A., Chang, Y. J., \& Hu, T. W. (1992). An exploration of the content of self-concept of Taiwan university students. Taipei: Institute of Ethnicity, Academia Sinica. 